\title{
PLANO DE GERENCIAMENTO ATMOSFÉRICO PARA A PRAÇA BRASIL, BELÉM-PA
}

Lucas da Veiga Cabral - lucsvcabral@gmail.com

Universidade do Estado do Pará

João Vitor Santos Ferreira - ferreirajvsantos@gmail.com

Universidade do Estado do Pará

Amanda Carolina Santos de Matos - amandacmatos@outlook.com

Universidade do Estado do Pará

Rebeca Rodrigues Crespo Teixeira-rebecarct@yahoo.com.br

Universidade do Estado do Pará

Ana Lívia Cantuária Andrade - al.cantuaria@gmail.com

Universidade do Estado do Pará

Victor Marcos dos Santos Catete Fonseca - vsanttos1@gmail.com

Universidade do Estado do Pará

Eddie Arlley de Albuquerque Gonçalves - eddie.arlley@gmail.com

Universidade do Estado do Pará

Eliane de Castro Coutinho - elianerik@gmail.com

Universidade do Estado do Pará 


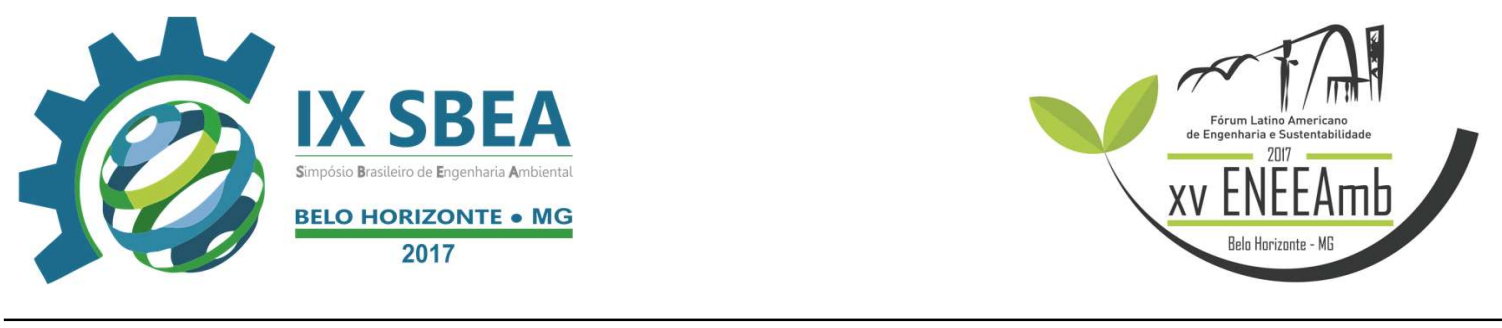

\section{RESUMO}

Com o acelerado crescimento urbano nas últimas décadas, o meio ambiente acabou por degradar-se, uma vez que as cidades aumentaram sem que houvesse preocupação com a natureza, trazendo malefícios ao ambiente e ao próprio homem, afetando sua saúde. Apesar da degradação dos espaços naturais nas cidades, sabe-se que a natureza proporciona uma melhor qualidade de vida à população. Assim, é importante que o poder público tenha cuidado com estes espaços. Neste sentido, foi realizado, na Praça Brasil, Belém-PA, um estudo visando a elaboração de um Plano de Gerenciamento Atmosférico deste local, identificando suas principais fontes de poluição atmosférica, analisando as atividades realizadas no espaço, diagnosticando a geração e impacto dos poluentes atmosféricos na praça e sugerindo soluções para esta problemática. Assim, foi feita uma visita à Praça Brasil, onde foram encontradas fontes de poluição atmosférica como veículos (pontos de ônibus e táxi), resíduos sólidos incorretamente depositados e canteiros de obras ao redor da praça. Estas fontes poderiam ter suas emissões de poluentes reduzidas com medidas simples, como a realocação de um dos pontos (de ônibus ou táxi) para que não fiquem muito próximos um do outro, o que poderia concentrar poluentes, colocação de tela ao redor dos prédios em construção, reduzindo a emissão de material particulado, e a disposição correta de rejeitos orgânicos, impedindo a exposição da população aos gases liberados pelos mesmos.

Palavras-chave: Meio ambiente; poluição atmosférica; fontes de poluição.

\section{INTRODUÇÃO/OBJETIVO}

No decorrer das últimas décadas, o crescimento populacional intensificou-se de forma acelerada, não havendo preocupação com o planejamento da cidade e da população, resultando em uma sociedade concentrada juntamente com as atividades corriqueiras dos seres humanos, sejam elas ecológicas, industriais, técnicas, dentre outras, que acabam por degradar o meio ambiente, oriundo de uma prática de uso desordenado e incoerente dos recursos naturais.

Atualmente, metade dos habitantes do planeta Terra vivem nas cidades, distribuídos em diversos países. Em virtude do grande volume populacional, surgimento, e forma de organização e crescimento, as cidades por resultar em um grande impacto do 


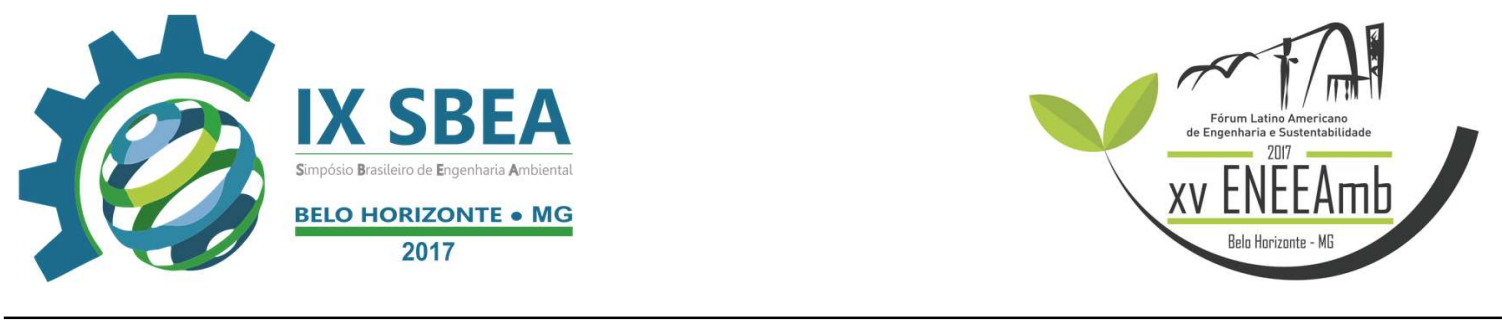

homem nos sistemas naturais (MILANO \& DALCIN, 2000). Assim, as cidades foram construídas com a finalidade de suprir as necessidades e facilitar a vida do homem, já que os serviços e chances concentram-se em um determinado local. Todavia, em que pese seu lado positivo, há contradições, devido aos diversos problemas funcionais que acabam, muitas das vezes, prejudicando o ser humano e o meio ambiente. Dessa forma, pode-se dizer que um dos pontos negativos das cidades consiste na deterioração, por exemplo, dos ambientes abertos.

Sabe-se que o meio ambiente consiste em um dos principais fatores capazes de proporcionar uma qualidade de vida para os moradores da localidade. É fundamental que os agentes públicos responsáveis pelo planejamento das cidades conheçam e analisem as estruturas e funções destas, de modo que haja um cuidado acerca dos espaços abertos, tudo com o intuito de cuidar da cidade em si (MILANO \& DALCIN, 2000, apud SILVA FILHO et al., 2012).

Neste sentido, o trabalho foi realizado na Praça Brasil, devido o espaço ser considerado uma unidade ambiental pertencente à cidade de Belém, capital do Estado do Pará. Para tanto, pode-se aplicar um Plano de Gerenciamento atmosférico. Este, por sua vez, implica, primeiramente, nas mudanças de hábitos, conscientização e comportamentos referentes às atitudes da população, fazendo-se necessário uma reeducação ambiental responsável por atender as práticas presentes no cotidiano da Praça Brasil, cujas principais formas de poluição perceptíveis, hoje, são os gases poluentes emitidos pelo tráfego de veículos automotores, poluição decorrente de construção civil existente próximo à Praça, dentre outros.

Destarte, o objetivo do presente artigo consiste na elaboração de um Plano de Gerenciamento Atmosférico da Praça Brasil - PA, verificando possíveis formas de minimizar os impactos ambientais, além de: a) identificar as principais fontes poluidoras do local; b) conhecer e analisar as atividades presentes na Praça Brasil; c) diagnosticar a geração dos poluentes e os impactos gerados, e, por fim; d) sugerir soluções para a problemática da poluição atmosférica na praça.

\section{METODOLOGIA}




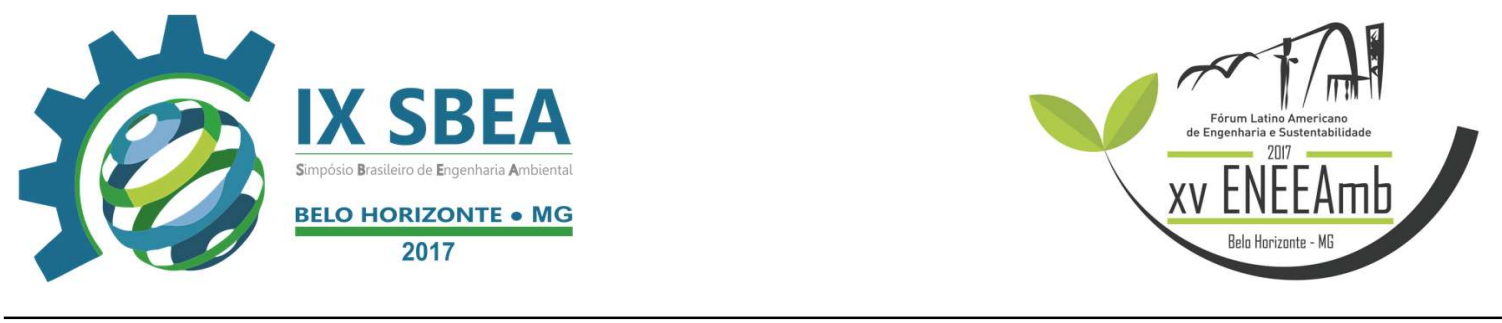

Para a realização deste trabalho foi necessária primeiramente uma pesquisa bibliográfica acerca do assunto para que este atendesse as normas e legislações vigentes, e posteriormente foram adotados os procedimentos de acordo com a bibliografia estudada. Os métodos utilizados seguem descritos a seguir.

\subsection{Referencial Teórico}

Segundo Silva (2006) o conceito da poluição ambiental do ar se divide em duas vertentes: a poluição natural e a poluição antropogênica. Dentre os componentes da poluição não antropogênica (natural) podemos destacar o pó, pólen e esporos e os óleos essenciais.

Os poluentes atmosféricos podem ser elencados como poeiras fumaças e gases/vapores. Dentre as poeiras/fumaças podemos destacar: as poeiras não metálicas e metálicas. Dentre os gases/vapores podemos destacar: os óxidos de carbono; emissões gasosas ácidas; oxidantes; aerossóis, smog e etileno, dentre outros (MARC, 2009).

De acordo com o MMA (2017) fontes de emissão de poluentes podem ser as mais variadas possíveis. Pode-se considerar dois tipos básicos de fontes poluição: específicas e múltiplas. As fontes específicas são fixas em determinado território, ocupam na comunidade área relativamente limitada e permitem uma avaliação individual. As indústrias são exemplos de fontes específicas de poluição.

As fontes múltiplas podem ser fixas ou móveis, geralmente se dispersam pela comunidade, oferecendo grande dificuldade de serem avaliadas uma a uma. Um exemplo de fonte múltipla são os veículos automotores.

A quantidade e qualidade dos poluentes emitidos por este tipo de fonte dependem de vários fatores relacionados à fabricação. As matérias-primas e combustíveis envolvidos no processo, a eficiência do processo, o produto fabricado e o grau de medidas de controle de emissões influem diretamente no tipo e concentração do poluente expelido.

\subsection{Padrões de qualidade do ar}

O padrão de qualidade do ar define legalmente as concentrações máximas de um componente gasoso presente na atmosfera de modo a garantir a proteção da saúde e do bem estar das pessoas. Os padrões de qualidade do ar são baseados em estudos científicos 


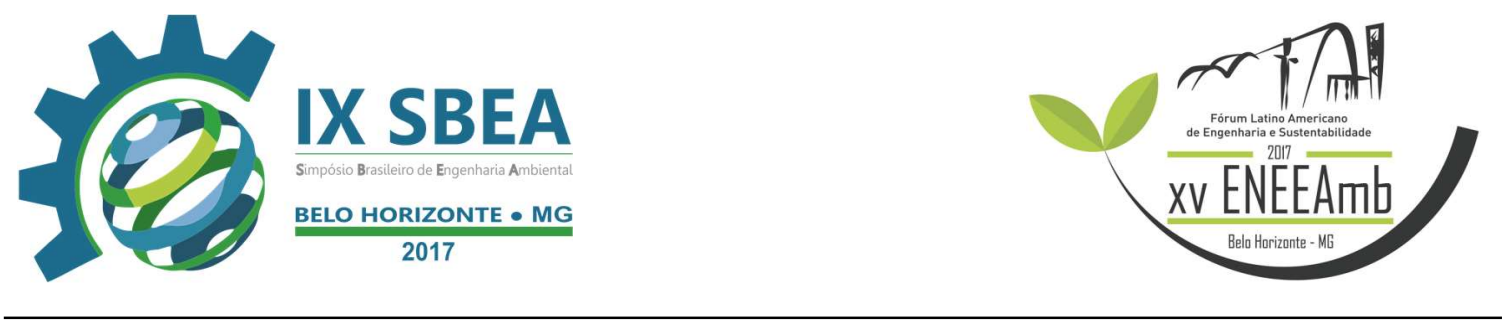

dos efeitos produzidos por poluentes específicos e são estabelecidos em níveis que possam propiciar uma margem de segurança adequada.

Através da Portaria Normativa $n^{\circ} 348$ de 14/03/90, o IBAMA (2017) estabelece os padrões nacionais de qualidade do ar. No Brasil são estabelecidos dois tipos de padrões de qualidade do ar: os primários e os secundários.

Os Padrões Primários de Qualidade do Ar são as concentrações de poluentes que se ultrapassadas poderão afetar a saúde da população. Podem ser entendidos como níveis máximos toleráveis de concentração de poluentes atmosféricos, constituindo-se em meta de curto e médio prazo.

São Padrões Secundários de Qualidade do Ar as concentrações de poluentes atmosféricos abaixo das quais se prevê o mínimo efeito adverso sobre o bem-estar da população, assim como o mínimo dano à fauna, flora, materiais e ao meio ambiente em geral. Podem ser entendidos como níveis desejados de concentração de poluentes, constituindo-se em meta de longo prazo.

São poluentes padronizados no Brasil: partículas totais em suspensão; fumaça; dióxido de enxofre (SO2); partículas inaláveis; monóxido de carbono (CO); ozônio (O3); dióxido de nitrogênio.

A Constituição Federal (BRASIL, 1988) estabelece o direito da população de viver em um ambiente ecologicamente equilibrado, caracteriza como crime toda ação lesiva ao meio ambiente, determina a exigência de que todas as unidades da Federação tenham reserva biológica ou parque nacional e todas as indústrias potencialmente poluidoras apresentem estudos sobre os danos que podem causar ao meio ambiente. Ainda se faz necessário elaborar leis que regulamentem os dispositivos constitucionais.

\section{3 Área de estudo}

Determinou-se a partir da pesquisa bibliográfica que seria mais adequado aplicar na área de estudo uma pesquisa qualitativa, onde seriam identificadas possíveis fontes de poluição atmosférica e tentar propor soluções.

A Praça Brasil está localizada na travessa Dom Pedro I, no bairro Umarizal em Belém do Pará (figura 1). Considerada como uma das atrações da cidade de Belém do 


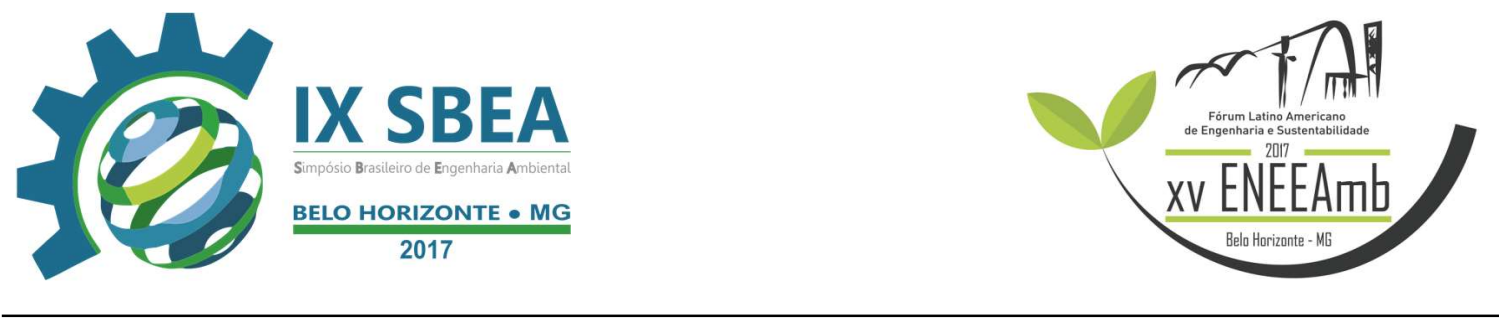

Pará, todos os dias recebem visitas com os mais diversos fins, entre eles o passeio, atividades físicas, atividade econômica.

Figura 1 - Vista de Satélite da Praça Brasil. Fonte: Google Maps.

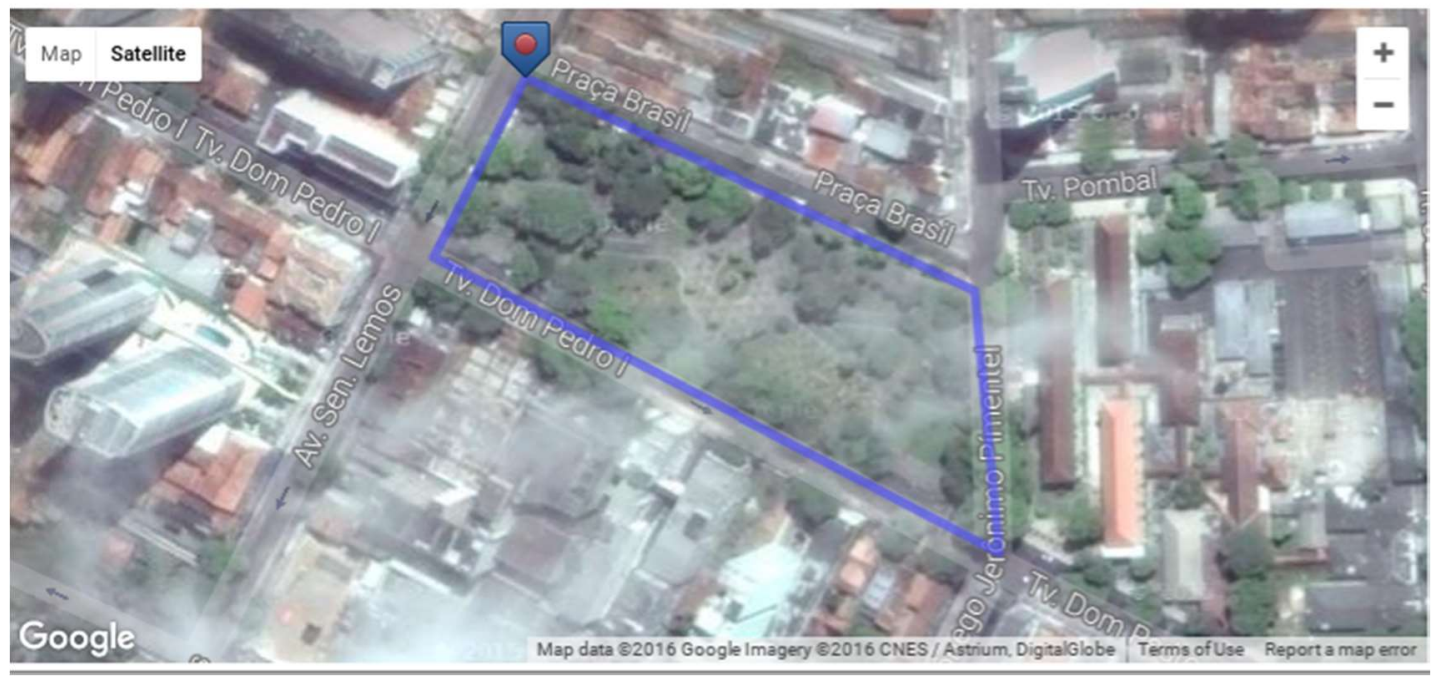

Durante a visita técnica realizada à Praça Brasil, que se deu durante o período vespertino, foram registradas em fotos possíveis fontes de poluição atmosférica de modo a constituir um levantamento qualitativo das fontes de emissões encontradas na praça, possibilitando a elaboração de medidas de atenuação destas.

Para a análise destas fontes de poluição utilizou-se as legislações descritas na sessão 3.2, que serviram de base para as análises realizadas.

\section{RESULTADOS E DISCUSSÃO}

O levantamento apurado das condições qualitativas da praça revelou um ambiente intensamente arborizado no centro de um dos bairros mais urbanizados da capital. No tempo de estadia da visita, foi possível notar uma intensa circulação de pessoas na praça, dentre pedestres casuais, trabalhadores informais e formais e desportistas. Além disso, de um ponto de vista estrutural, a praça apresentou um estado de conservação excelente, havendo boa manutenção dos canteiros e monumentos e com 

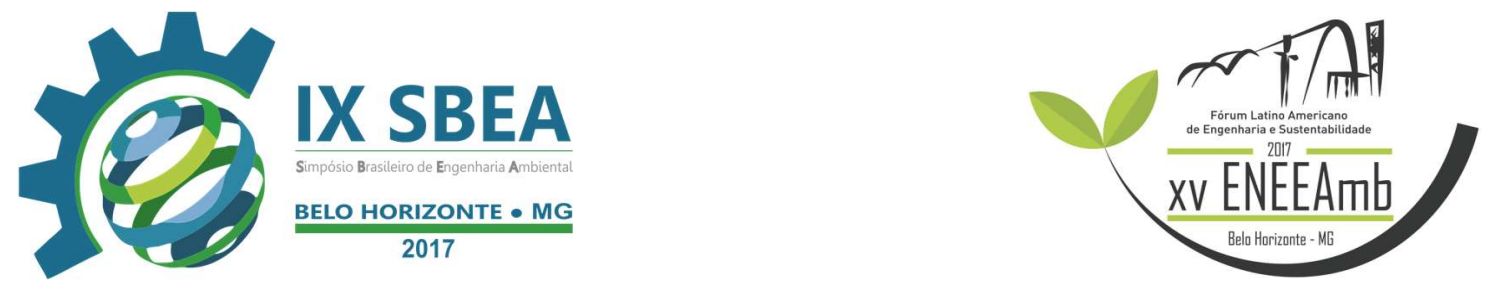

uma quantidade relativamente bem suprida de equipamentos urbanos destinados ao lazer e bem-estar público.

Não obstante, foi possível identificar alguns pontos críticos de geração de emissões atmosféricas e a consequente degradação da qualidade do ar da área de estudo. Em se tratando de uma área intensamente urbanizada, foram observadas ao redor da praça obras de construção civil e reformas em andamento (figuras 2A e 2B). Tais obras têm por característica principal a emissão de material particulado à atmosfera, os quais quando inalados em grande quantidade podem ocasionar diversas doenças respiratórias, como por exemplo, a silicose pulmonar.

Figura 2 - Obras de grande $(\mathrm{A})$ e pequeno $(\mathrm{B})$ porte situadas em frente à praça.

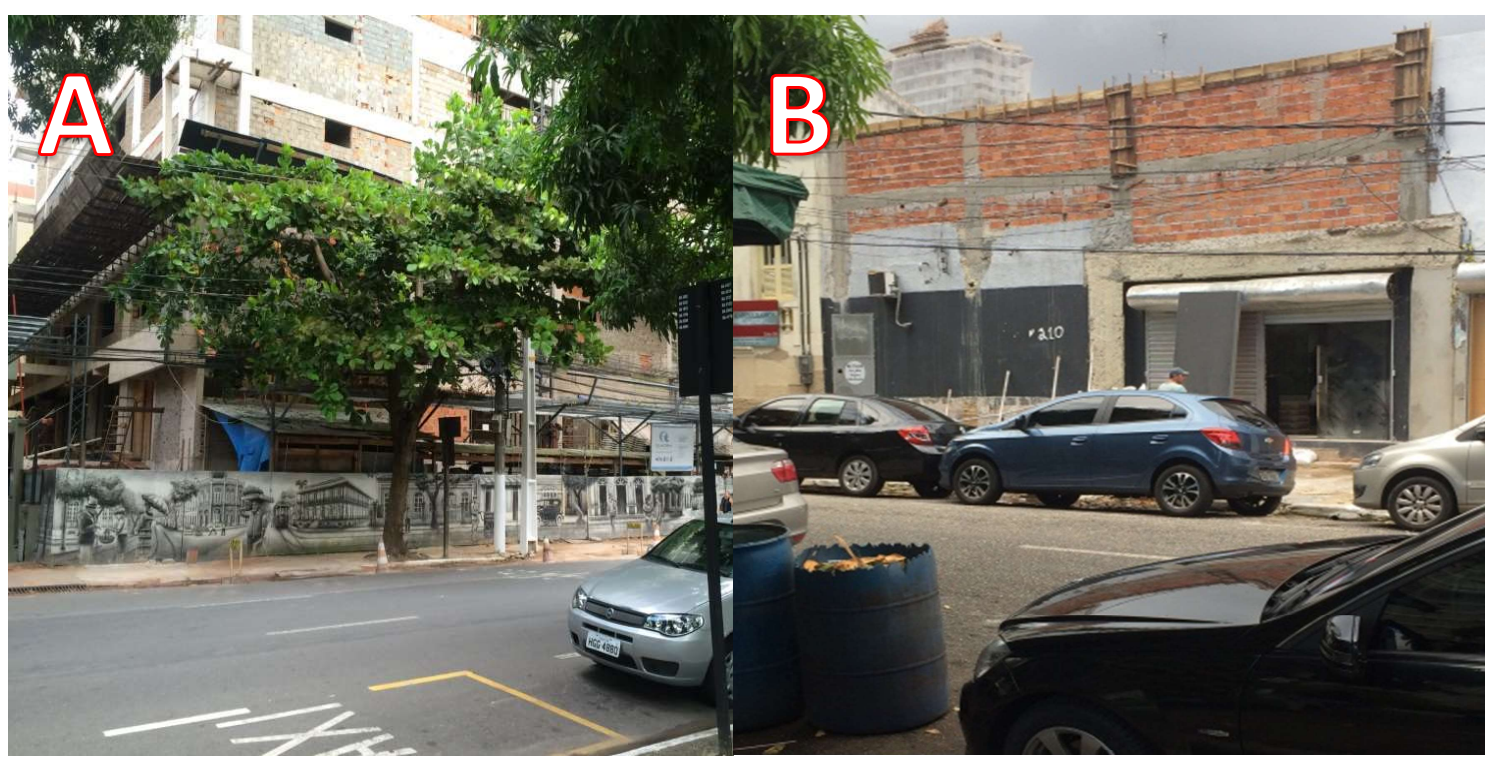

Existiam, no momento da visita, duas obras em andamento nos arredores da praça, sendo uma de grande porte (figura 2A), situada na Tv. Dom Pedro I, esquina com a Av. Senador Lemos, e outra de pequeno porte (figura 2B), situada na Tv. Praça Brasil esquina com a Av. Senador Lemos. Ambas se encontravam sem a devida proteção quanto à emissão de material particulado e resíduos, sujeitando dessa forma os frequentadores da praça a possíveis danos à saúde para o caso de exposições muito longas. A quantidade material particulado emitido pelas obras próximas à Praça Brasil poderia ser reduzida 
com a colocação de tela ao redor do prédio em construção, o que reteria o material, diminuindo ou impedindo que a população que transita ao redor esteja exposta a ele.

Também identificou-se outro ponto crítico no que diz respeito às barracas de alimentação na praça. Sendo um ambiente de lazer, constituído na forma de um espaço público, surgem espaços destinados ao comercio de alimentos e bebidas, como água-decoco, sanduíches etc. Tais empreendimentos encontram-se devidamente regulamentados pela prefeitura, organizados na forma de quiosques padronizados. Ainda assim, inevitavelmente a atividade comercial traz consigo a geração de passivos tendo em vista a produção em escala considerável de material orgânico, como resíduos sólidos.

A decomposição do material orgânico, apesar de um processo natural, acarreta na produção de substâncias que quando volatilizadas são responsáveis por provocar alterações na qualidade atmosférica do local. Ainda que se tratando do comércio devidamente regularizado pela prefeitura municipal, com fontes de coleta de resíduos devidamente dispostas, foi possível observar a destinação incorreta de resíduos na praça (figuras 3A e 3B). Este problema poderia ser resolvido com uma maior conscientização da população em relação ao destino correto do lixo e maior quantidade de lixeiras no local, o que reduziria a poluição na Praça Brasil em relação aos resíduos sólidos e, consequentemente, aos gases emitidos pelos mesmos.

Figura 3 - Pontos de lançamento de resíduos, próximo a quiosques de alimentação (A) e em uma esquina da praça (B).

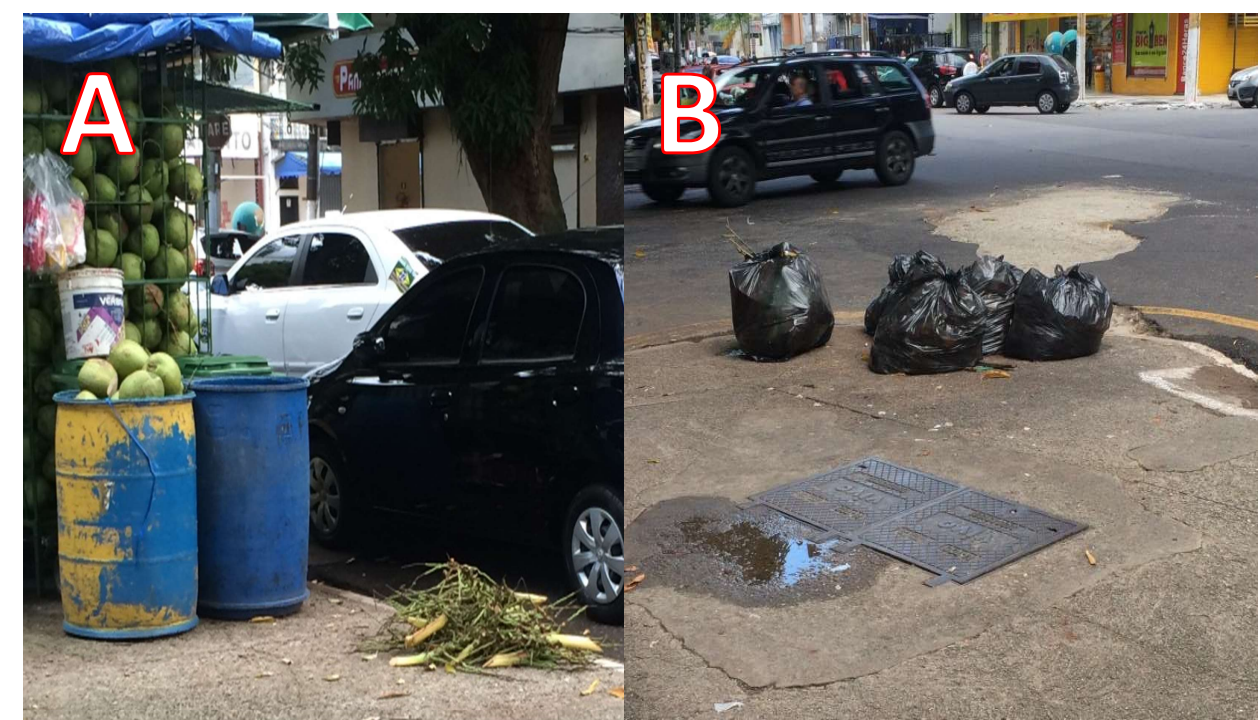




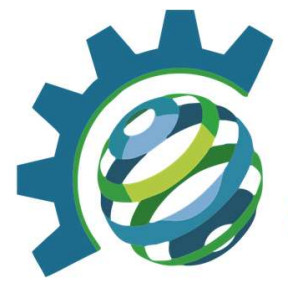

Notou-se também que o ponto mais crítico identificado reside no tráfego de veículos ao redor da praça. Devido à sua localização entre duas avenidas movimentadas da cidade, há um intenso fluxo de carros, ônibus, motos etc, que é responsável pela elevação na concentração de poluentes emitidos a partir do funcionamento dos motores a combustão. Na Avenida Senador Lemos, próximo à esquina com a Travessa D. Pedro I, encontram-se um ponto de táxi, do lado esquerdo da rua, e um ponto de ônibus, do lado direito (figura 4). Por se localizarem no mesmo perímetro e, logo, muito próximos um do outro, os dois pontos produzem gases poluentes que acabam por concentrar-se em uma região muito reduzida. Uma alternativa para a redução da poluição atmosférica causada por veículos nesta área seria o deslocamento de um dos pontos, de táxi ou de ônibus, para outro local.

Figura 4 - Pontos de ônibus e de táxi na Av. Senador Lemos, ao lado da Praça Brasil.

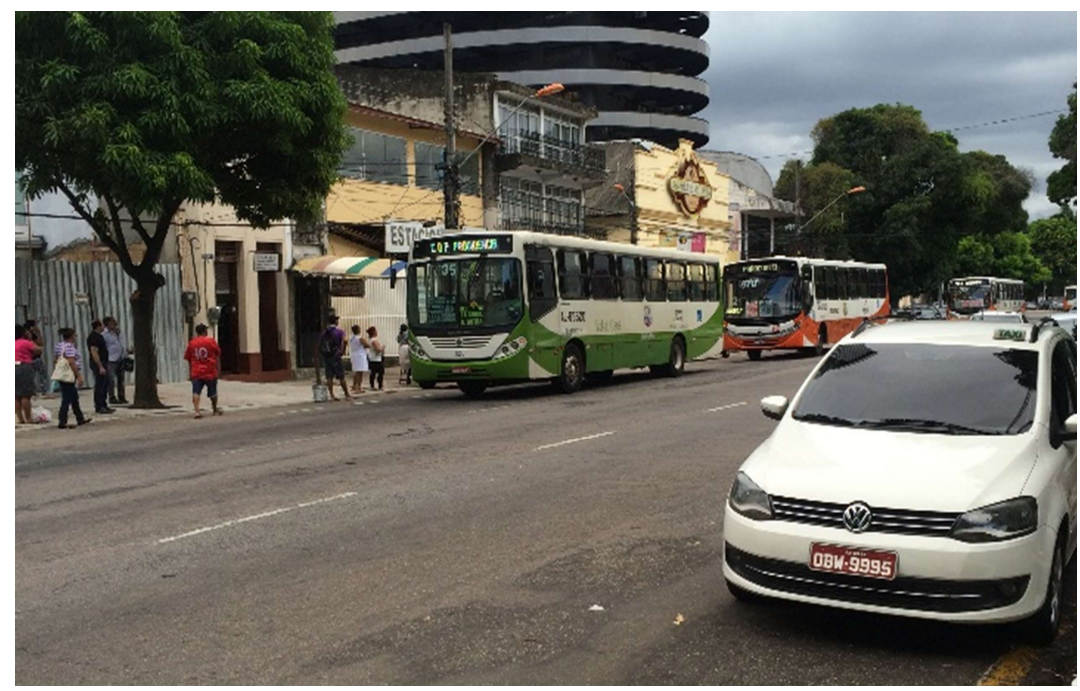

\section{CONCLUSÕES/RECOMENDAÇÕES}

A partir desta pesquisa, percebe-se que, apesar da grande importância da Praça Brasil para a cidade de Belém como espaço de lazer urbano e da grande quantidade de pessoas que por ela transitam diariamente, foi possível encontrar diversas fontes de poluição atmosférica no local. Em concentrações não permitidas, as substâncias emitidas por essas fontes podem causar problemas de saúde, principalmente àqueles que estão 


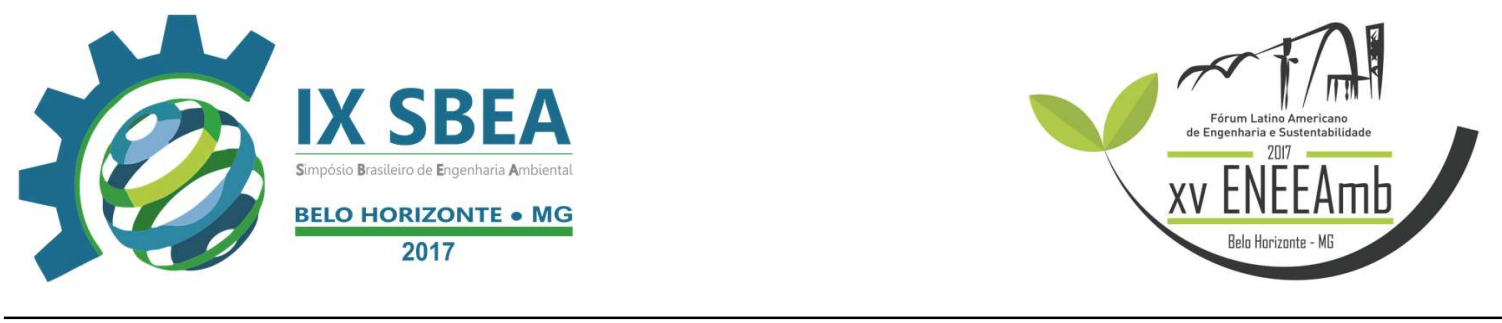

expostos a elas com frequência. Portanto, é de extrema importância que tais fontes tenham suas emissões diminuídas, realocadas para locais com maior dispersão, ou então, se possível, que sejam eliminadas e substituídas por alternativas menos poluentes, fazendo com que as emissões possam se enquadrar nos padrões de qualidade do ar estabelecidos pela legislação vigente.

\section{REFERÊNCIAS BIBLIOGRÁFICAS}

BRASIL. Constituição (1988). Constituição da República Federativa do Brasil. Brasília: Senado Federal - Centro Gráfico, 1988. 292 p.

IBAMA (Instituto Brasileiro do Meio Ambiente). Portaria Normativa n. ${ }^{\circ}$ 348, de 14/03/1990. Dispõe sobre os padrões de qualidade do ar e as concentrações de poluentes atmosféricos. Disponível

em: http://www.ibama.gov.br/sophia/cnia/legislacao/IBAMA/PT0371-210599.PDF. Acesso em: 30 mar. 2017.

MARC P. S.; JANET J. Ecologia e saúde - uma medicina para o futuro. Lisboa: Instituto Piaget, 2009. $431 \mathrm{p}$.

MILANO, M.; DALCIN, E. Arborização das vias públicas. Rio de Janeiro: LIGHT, 2000. $226 \mathrm{p}$.

MMA (Ministério do Meio Ambiente). Qualidade do ar. Disponível em: http://www.mma.gov.br/cidades-sustentaveis/qualidade-do-ar. Acesso em: 30 mar. 2017.

SILVA, A. L. M. Direito do meio ambiente e dos recursos naturais. São Paulo: Revista dos Tribunais, 2006. 487 p.

SILVA FILHO, D. F. S.; COSTA, F. P. S.; POLIZEL, J. Planejamento da arborização urbana da Cidade de Engenheiro Coelho-SP: uso de SIG e de inventário amostral. Geografia em Atos. Presidente Prudente, v.1, n.12, p.1-8, 2012. 